Research Paper

\title{
Metastasis patterns and prognosis in breast cancer patients aged $\geq 80$ years: a SEER database analysis
}

\author{
Youming Han ${ }^{1,2}$, Zhilin Sui ${ }^{1}$, Yongsheng Jia ${ }^{3}$, Hailong Wang ${ }^{1}$, Yan Dong ${ }^{4}$, Hongdian Zhang ${ }^{1}$, Zhigang Li², \\ Zhentao $\mathrm{Yu}^{1,5 凶}$
}

1. Department of Esophageal Cancer, Tianjin Medical University Cancer Institute and Hospital, National Clinical Research Center for Cancer, Key Laboratory of Cancer Prevention and Therapy, Tianjin's Clinical Research Center for Cancer, Tianjin 300060, China.

2. Department of Respiratory medicine, Binhai Hospital of Tianjin Medical University General Hospital, Tianjin, 300456, China.

3. Department of Breast Oncology, Tianjin Medical University Cancer Institute and Hospital, Tianjin, 300060, China.

4. Tianjin Teda Hospital, Tianjin, 300456, China.

5. Department of Thoracic Surgery, National Cancer Center, National Clinical Research Center for Cancer, Cancer Hospital \& Shenzhen Hospital, Chinese Academy of Medical Sciences and PeKing Union Medical College, Shenzhen, 518116, China.

$\triangle$ Corresponding author: Zhentao Yu, E-mail: yuzhentao@tjmuch.com; Department of Esophageal Cancer, Tianjin Medical University Cancer Institute and Hospital, Key Laboratory of Cancer Prevention and Therapy of Tianjin City, Tianjin, 300060, China. Phone: 0086-022-23340123, Fax: 0086-22-23359984.

(c) The author(s). This is an open access article distributed under the terms of the Creative Commons Attribution License (https://creativecommons.org/licenses/by/4.0/). See http://ivyspring.com/terms for full terms and conditions.

Received: 2021.06.12; Accepted: 2021.08.22; Published: 2021.09.03

\begin{abstract}
Background: This study aimed to investigate the metastasis patterns and prognosis of breast cancer (BC) in patients aged $\geq 80$ years with distant metastases, as the current literature lacks studies in this population.

Methods: A retrospective, population-based study using data from the Surveillance, Epidemiology, and End Results (SEER) database was conducted to evaluate 36,203 patients with BC from 2010 to 2016. Patients were classified into three groups, the older group (aged $\geq 80$ years), middle-aged group (aged 60-79 years), and younger group (aged $<60$ years). The role of age at the time of BC diagnosis in metastasis patterns was investigated, and the survival of different age groups of patients with $\mathrm{BC}$ was assessed.

Results: Overall, 4,359 (12\%) patients were diagnosed with BC at age $\geq 80$ years, 19,688 (54\%) at 60-79 years, and $12,156(34 \%)$ at $<60$ years. Compared with the other two groups, those in the older group had a lower rate of treatment acceptance. Statistical analysis revealed that older patients were more likely to have lung invasion only (odds ratio [OR]: 1.274, 95\% confidence interval [Cl]: 1.163-2.674) and less likely to have bone invasion only (OR: $0.704,95 \% \mathrm{Cl}$ : $0.583-0.851$ ), brain invasion only (OR: $0.329,95 \% \mathrm{Cl}: 0.153-0.706)$, or multiple metastatic sites (OR: $0.361,95 \% \mathrm{Cl}: 0.284-0.458$ ) compared to the other two groups. Age at diagnosis was an independent prognostic factor for survival. The older group had the worst overall survival (OS, $\mathrm{P}<0.001$ ) and $\mathrm{BC}$-specific survival $(\mathrm{CSS}, \mathrm{P}<0.001$ ). Furthermore, patients aged $\geq 80$ years with only liver metastasis had the worst CSS and OS.

Conclusion: Patients aged $\geq 80$ years were less likely to be receptive to cancer-related therapy and had the highest cancer mortality rate among all patients. Our findings will hopefully help clinicians develop more appropriate modalities of cancer treatment in elderly BC patients.
\end{abstract}

Key words: breast cancer, elderly patients, age-related, metastasis, prognosis

\section{Introduction}

Breast cancer $(\mathrm{BC})$ is the most widely diagnosed cancer in women worldwide. In 2019, a total of 268,600 people were diagnosed with BC, and 41,488 females died of the disease [1]. Survival rates in elderly patients with BC have improved in recent decades, which is largely attributed to the expanding efforts in early detection and recent advances in modalities of cancer treatment. Despite these, BC remains the second leading cause of cancer-related mortality in the United States, where 11,002 elderly patients aged $\geq 80$ years were estimated to have died of BC in 2019. By 2030, nearly $20 \%$ of US population will be older adults (aged $\geq 65$ years), which is one in every five persons or 70 million people [2]. Metastases in organs distant from the primary site have been the main cause of mortality among patients with $\mathrm{BC}$. The most common sites of metastasis include bone, brain, lungs, and liver [3]. 
In current practice, older patients are generally not ideal candidates for large clinical trials and might be less likely to receive treatment [4]. The decline in physical function associated with aging may be the reason for the unwillingness to pursue aggressive therapy for both patients and doctors [5]. A previous study showed that $61 \%$ of patients aged $>75$ years with stages I to III triple-negative $\mathrm{BC}$ did not receive chemotherapy, in contrast to $5 \%$ of patients aged $<64$ years $(\mathrm{P}<0.001)$ who were declined chemotherapy. Nearly $12 \%$ of patients aged $>75$ years were not evaluated by an oncologist [6]. Moreover, it was found that elderly individuals were less likely to receive treatment compared to young women, regardless of the cancer type. This conservative approach has shown to have a marked negative effect on BC-specific survival in older BC patients than in younger ones [7]. On the contrary, another study showed some survival benefits to elderly patients with hormone receptor-positive $\mathrm{BC}$ who received endocrine treatment [8].

However, to our knowledge, population-based studies describing the role of age in metastatic heterogeneity of $\mathrm{BC}$ are limited [9]. Therefore, this study aimed to investigate the metastasis patterns and prognosis of patients with $\mathrm{BC}$ aged $\geq 80$ years.

\section{Material and methods}

\section{Data collection}

We used the Surveillance, Epidemiology, and End Results (SEER) database (SEER * Stat 8.3.6 version) to filter and narrow down the information to a representative population of patients for this research (http://seer.cancer.gov/). SEER is generally considered to be the gold standard for data quality among cancer registries, with near-complete case ascertainment and microscopic confirmation [10]. Since this study used registry data, approval was obtained from the Ethical Committee and Institutional Review Board of Tianjin Medical University Cancer Institute and Hospital. The methods were based on approved guidelines.

\section{Study population}

We utilized SEER population-based data to analyze distant metastasis patterns and prognosis of patients in different age groups and BC subtypes in a large cohort of the $\mathrm{BC}$ population, including patients aged $\geq 80$ years. We limited this study population based on the following criteria: (1) age at diagnosis $\geq 18$ years' old, (2) primary site at the breast and microscopically confirmed primary breast cancer, (3) only one malignant primary tumor, and (4) diagnosis between 2010 and 2016. Patients who did not meet these criteria were excluded. Patients were divided into three groups according to age (older group: aged $\geq 80$ years; middle-aged group: aged $60-79$ years; and younger group: aged $<60$ years). Ultimately, a total of 36,203 patients were included.

In addition to age, other important clinicopathological parameters known to contribute individually to outcomes were also included in the analysis. The following factors were extracted: demographic factors (year of diagnosis, age at diagnosis $\geq 18$ years old, and race), clinicopathological factors (tumor size [T stage], lymph node status [N stage]), TNM stage, histologic grade (well differentiated, moderately differentiated, poorly differentiated, undifferentiated, unknown), primary site, and morphology of ICD-O-3 (8000/ 8033/8010/8013/8022/8032/8035/8046/8050/8070/ $8071 / 8140 / 8141 / 8200 / 8201 / 8211 / 8230 / 8240 / 8246 /$ $8249 / 8255 / 8260 / 8310 / 8315 / 8343 / 8401 / 8480 / 8481 /$ $8490 / 8500 / 8501 / 8502 / 8503 / 8504 / 8507 / 8510 / 8520 /$ 8522/8523/8524/8530/8541/8543/8572/8573/8574/ $8575 / 8980 / 9020$ ), breast subtype (luminal A, luminal B, triple-negative, HER2-enriched), therapeutic interventions (surgery of primary site in terms of the "breast surgery codes C50.0-C50.9", radiotherapy, and chemotherapy), and survival factors (death events and survival months). The patients' pathological TNM stages were confirmed using the $7^{\text {th }}$ edition of the American Joint Committee on Cancer staging system.

\section{Statistical analysis}

The primary outcomes were overall survival (OS) and BC-specific survival (CSS). To clarify the survival benefit of locoregional and systemic treatment for older patients, both OS and CSS of the three age groups were compared in terms of metastasis to different single organs or a combination of multiple organs. OS was defined as the time from the diagnosis of breast cancer to death due to any cause or the date of the last follow-up. CSS was calculated as the time from the diagnosis of breast cancer to death due to BC. One-way analysis of variance was utilized to compare demographic and clinical characteristics of patients among age groups. Comparison of categorical variables was performed using Pearson's chi-square test, and the Kaplan-Meier method was adopted to depict survival curves, with the log-rank test being performed to detect the differences among the curves. Univariate and multivariate Cox regression models were applied to identify risk factors for OS and BC-CSS; odds ratios (ORs) and 95\% confidence intervals (CIs) were calculated. A p-value less than 0.05 was considered statistically significant. Forest plots were created using GraphPad Prism 8.2.4 (GraphPad Software, San Diego, CA, USA). All the other calculations were 
performed using SPSS 21.0 statistical software (SPSS Inc. Chicago, IL, USA).

\section{Results}

\section{Demographics}

In total, 36,203 BC patients were enrolled in the current study. Among them, 4,359 (12\%) patients were diagnosed at the age of $\geq 80$ years, 19,688 (54\%) patients at $60-79$ years, and $12,156(34 \%)$ patients at $<60$ years. In the three groups, 24,560 cases $(67.8 \%)$ had luminal A subtype, 2,979 cases (8.2\%) had luminal B subtype, 1,418 cases $(3.9 \%)$ had HER2-enriched subtype, and 5,122 cases (14.1\%) had triple-negative $\mathrm{BC}$. Regarding the metastasis site, 1,609 patients were diagnosed with only bone metastases, 139 with only brain metastases, 112 with only liver metastases, 252 with only lung metastases, and 1,637 with metastases to multiple sites. Statistically significant differences in clinicopathological characteristics among the different age groups with BC are summarized in Table 1. Interestingly, among the three populations, there were more white patients than any other ethnic group in the older age group $(87.8 \%$ vs. $83.8 \%$ and $73.8 \%$, respectively, $\mathrm{P}<0.001$ ). Notably, a high proportion of the young patients had aggressive luminal $\mathrm{A}$ and triple-negative subtypes. The proportion of luminal B, HER2, and triple-negative subtypes was significantly higher in patients younger than 60 years $(\mathrm{P}<0.001)$. Furthermore, significant differences in treatment modalities were found among the different age groups. For instance, compared with the other two groups, the older group had a lower rate of treatment acceptance of surgery $(86.6 \%$ vs. $91.6 \%$ vs. $87.3 \%, \mathrm{P}<0.001)$, radiotherapy $(80.1 \%$ vs. $89.3 \%$ vs. $89.1 \%, \mathrm{P}<0.001)$, and chemotherapy $(10.8 \%$ vs. $36.5 \%$ vs. $67.4 \%, \mathrm{P}<0.001)$.

\section{Correlation between age and metastasis patterns of BC}

$B C$ patients with single and multiorgan metastatic disease were analyzed as shown in Figure 1. Evidently, the three cohorts presented most frequently with bone metastasis and least frequently with brain and liver metastases. Compared with the other two groups, the older group showed fewer occurrences of brain-only metastatic disease $(0.85 \%$ vs. $3.23 \%$ and $1.83 \%$, respectively $\mathrm{P}<0.001)$. We also found that the older patients had a lower proportion of multiple metastatic sites $(2.64 \%)$ than middle-aged $(3.86 \%)$ and younger patients $(6.28 \%) \quad(\mathrm{P}<0.001)$. Notably, there were some differences in the patterns of metastasis among different subtypes in the three age groups. However, in all subtypes of BC, a similar trend was that the incidence of bone metastasis was observed to be the highest in all three age groups. Compared with the other two groups, the older group had fewer occurrences of brain-only metastatic disease and liver-only metastatic disease in luminal A subtype $(0.03 \%$ and $0.07 \%$, respectively), luminal B subtype $(0.33 \%$ and $0 \%$, respectively), HER2-enriched subtype $(0 \%$ and $0 \%$, respectively), and triplenegative subtype $(0.38 \%$ and $0.19 \%$, respectively $)$ $(\mathrm{P}<0.001)$ (Fig. 2).

Table 1. Demographic and clinical characteristics of the cohort

\begin{tabular}{|c|c|c|c|c|}
\hline Characteristics & $\begin{array}{l}<60 \text { yrs, } \\
n=12156(\%)\end{array}$ & $\begin{array}{l}60-79 \text { yrs, } \\
n=19688(\%)\end{array}$ & $\begin{array}{l}\geq 80 \text { yrs, } \\
n=4359(\%)\end{array}$ & P-value \\
\hline Race & & & & $<0.001$ \\
\hline Black & $2127(17.5)$ & $2032(10.3)$ & $312(7.4)$ & \\
\hline White & $8974(73.8)$ & $16490(83.8)$ & $3826(87.8)$ & \\
\hline Other a & $1055(8.7)$ & $1166(5.9)$ & $221(4.9)$ & \\
\hline Gender & & & & $<0.001$ \\
\hline Male & $56(0.5)$ & $159(0.8)$ & $54(1.2)$ & \\
\hline Female & $12100(99.5)$ & $19529(99.2)$ & 4305 (98.8) & \\
\hline Laterality & & & & 0.188 \\
\hline Left & $6184(50.9)$ & $9844(50.0)$ & $2245(51.5)$ & \\
\hline Right & $5904(48.6)$ & $9720(49.4)$ & $2082(47.8)$ & \\
\hline Other $b$ & $68(0.6)$ & $124(0.6)$ & $32(0.7)$ & \\
\hline Histology & & & & $<0.001$ \\
\hline IDC & $9236(76.0)$ & $13980(71.0)$ & $2888(66.3)$ & \\
\hline ILC & $920(7.6)$ & $2247(11.4)$ & $577(13.2)$ & \\
\hline Mix/Other ${ }^{c}$ & $2000(16.5)$ & 3461 (17.6) & $894(20.5)$ & \\
\hline Grade & & & & $<0.001$ \\
\hline I & $1732(14.2)$ & 4448 (22.6) & $877(20.1)$ & \\
\hline II & 3990 (32.8) & $8486(43.1)$ & $1886(43.3)$ & \\
\hline III & $5491(45.2)$ & 5497 (27.9) & $1253(28.7)$ & \\
\hline IV & $79(0.6)$ & $56(0.3)$ & $14(0.3)$ & \\
\hline Unknown & 864 (7.1) & $1201(6.1)$ & $329(7.5)$ & \\
\hline Stage & & & & $<0.001$ \\
\hline I & 3883 (31.9) & $10249(52.1)$ & 1987 (45.6) & \\
\hline II & 3368 (27.7) & $4795(24.4)$ & $1186(27.2)$ & \\
\hline III & $2924(24.1)$ & $2716(13.8)$ & $742(17.0)$ & \\
\hline IV & 1981 (16.3) & $1928(9.8)$ & 444 (10.2) & \\
\hline Intrinsic type & & & & $<0.001$ \\
\hline Luminal A & $7233(59.5)$ & $14270(72.5)$ & 3057 (70.1) & \\
\hline Luminal B & $1234(10.2)$ & 1439 (7.3) & $306(7.0)$ & \\
\hline HER2-enriched & $646(5.3)$ & $632(3.2)$ & $140(3.2)$ & \\
\hline Triple-negative & 2392 (19.7) & $2204(11.2)$ & $526(12.1)$ & \\
\hline Unknown & $651(5.4)$ & $1143(5.8)$ & $330(7.6)$ & \\
\hline Surgery & & & & $<0.001$ \\
\hline Yes & $10616(87.3)$ & 18037 (91.6) & 3775 (86.6) & \\
\hline No/Unknown & $1540(12.7)$ & $1651(8.4)$ & $584(13.4)$ & \\
\hline Radiotherapy & & & & $<0.001$ \\
\hline Yes & $10828(89.1)$ & 17576 (89.3) & $3491(80.1)$ & \\
\hline No/Unknown & 1328 (10.9) & $2112(10.7)$ & 868 (19.9) & \\
\hline Chemotherapy & & & & $<0.001$ \\
\hline Yes & $8193(67.4)$ & $7179(36.5)$ & $470(10.8)$ & \\
\hline No/Unknown & $3963(32.6)$ & $12509(63.5)$ & 3889 (89.2) & \\
\hline
\end{tabular}

Notes: a Other races included American Indians, Asians, and Pacific Islanders; b Other laterality included paired site, but no information concerning laterality was

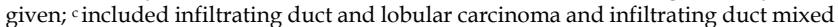
with other types of carcinoma;

Abbreviations: IDC, Infiltration Ductal Cancer; ILC, Infiltration Lobular Cancer; Grade I, well differentiated; Grade II, moderately differentiated; Grade III, poorly differentiated; Grade IV, undifferentiated anaplastic. 


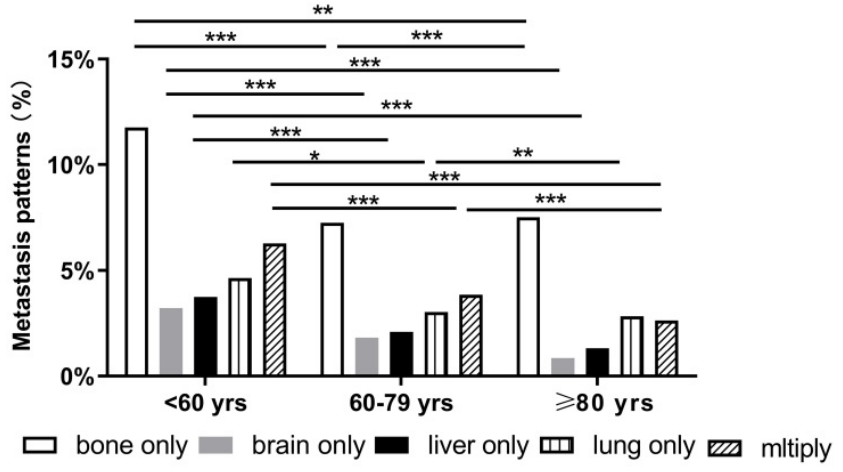

Figure 1. Distant metastatic patterns of breast cancer $\left({ }^{*} \mathrm{p}<0.05\right.$, **p $<0.01$, ***p $<$ $0.001)$.

\section{Risks examined for association with different metastasis sites}

In the logistic regression models adjusted for race, subtypes, histologic grade, surgery, radiotherapy, chemotherapy, as well as $\mathrm{T}$ stage and $\mathrm{N}$ stage, the odds for bone-only metastasis (OR: 0.704, 95\% CI: 0.583-0.851), brain-only metastasis (OR: 0.329, 95\% CI: 0.153-0.706), and multiple sites metastasis (OR: $0.361, \quad 95 \%$ CI: $0.284-0.458)$ significantly decreased in the older groups compared to those in the younger group (Fig. 3A-C). Additionally, there was no significant difference in odds for liver-only metastasis among the three groups (OR: 0.805, 95\% CI: 0.540-1.200 for middle-aged group, OR: $0.491,95 \% \mathrm{CI}$ : $0.188-1.282$ for older group, $p>0.05$ ) (Fig. 3D). On the other hand, the older patients had higher odds for
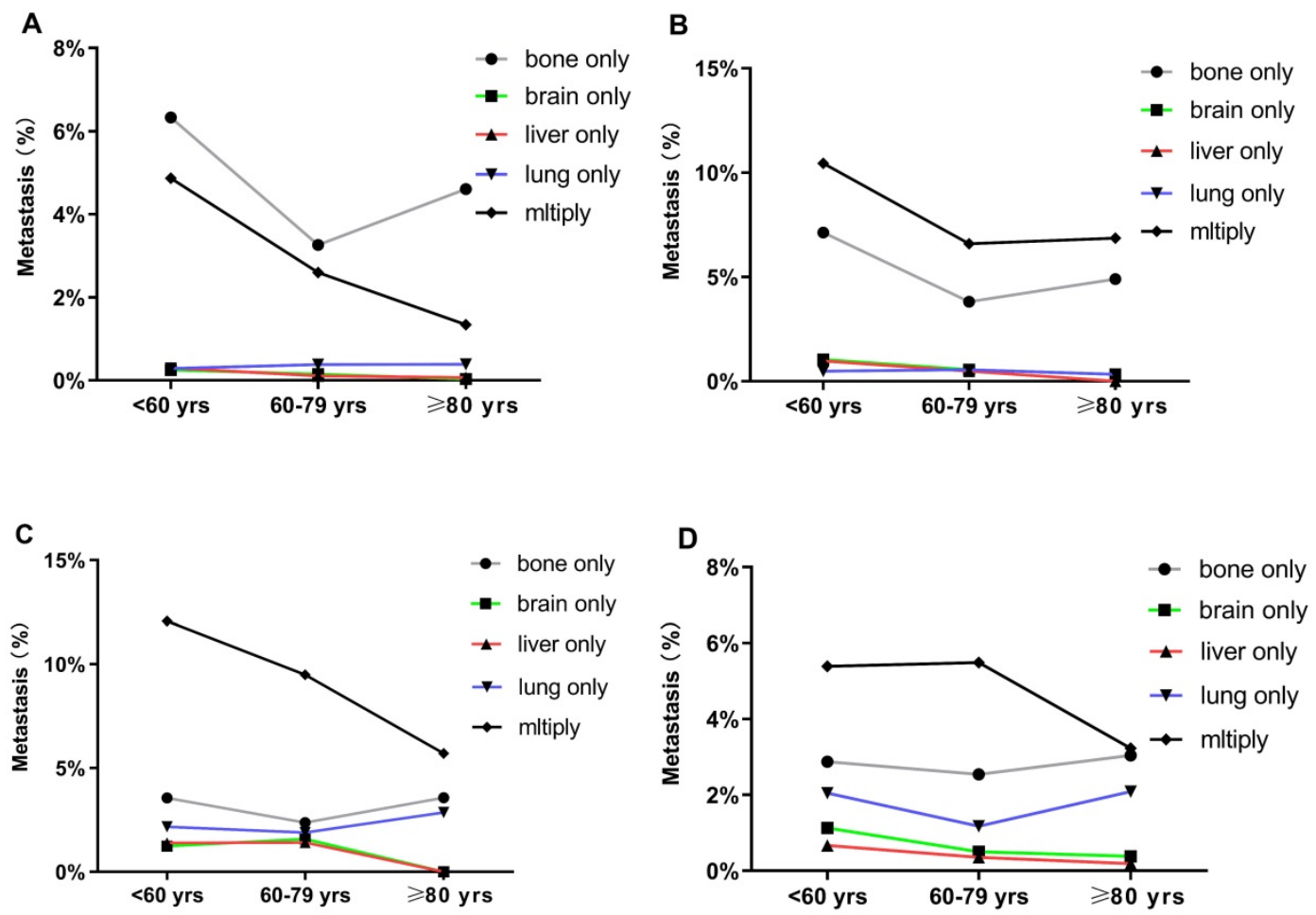

Figure 2. Distant metastatic patterns of breast cancer in different age groups. Metastasis patterns of (A) luminal A breast cancer; (B) luminal B breast cancer; (C) HER2-enriched breast cancer; and (D) triple-negative breast cancer were analyzed. 
Table 2. Univariate and multivariate analysis of the cancer-specific survival and overall survival of the study population

\begin{tabular}{|c|c|c|c|c|c|c|c|c|}
\hline \multirow[t]{3}{*}{ Characteristics } & \multicolumn{4}{|l|}{ CSS } & \multicolumn{4}{|l|}{ OS } \\
\hline & \multicolumn{2}{|l|}{ Univariate } & \multicolumn{2}{|l|}{ Multivariate } & \multicolumn{2}{|l|}{ Univariate } & \multicolumn{2}{|l|}{ Multivariate } \\
\hline & OR $(95 \% \mathrm{CI})$ & P-value & OR $(95 \%$ CI $)$ & P-value & OR $(95 \%$ CI $)$ & P-value & OR $(95 \% \mathrm{CI})$ & P-value \\
\hline \multicolumn{9}{|l|}{ Age } \\
\hline$<60$ yrs & 1 & & & & 1 & & & \\
\hline $60-79$ yrs & $1.081(1.036-1.128)$ & 0.000 & $1.106(1.058-1.156)$ & 0.000 & $0.932(0.911-0.953)$ & 0.000 & 1.054 (1.029-1.080) & 0.000 \\
\hline$\geq 80 \mathrm{yrs}$ & 1.369 (1.128-1.466) & 0.000 & $1.402(1.300-1.512)$ & 0.000 & $1.053(1.017-1.090)$ & 0.003 & $1.136(1.095-1.180)$ & 0.000 \\
\hline \multicolumn{9}{|l|}{ Race } \\
\hline Black & $1.122(1.027-1.225)$ & 0.011 & $1.154(1.056-1.261)$ & 0.002 & 1.178 (1.121-1.237) & 0.000 & 1.087 (1.034-1.142) & 0.001 \\
\hline White & $1.017(0.940-1.102)$ & 0.671 & $1.050(0.970-1.138)$ & 0.288 & $0.952(0.913-0.992)$ & 0.019 & $0.985(0.945-1.027)$ & 0.485 \\
\hline Other & 1 & & 1 & & 1 & & 1 & \\
\hline \multicolumn{9}{|l|}{ Gender } \\
\hline Male & 1 & & 1 & & 1 & & 1 & \\
\hline Female & 1.115 (0.902-1.377) & 0.314 & $1.110(0.897-1.373)$ & 0.337 & $0.834(0.740-0.941)$ & 0.003 & $0.935(0.829-1.055)$ & 0.274 \\
\hline \multicolumn{9}{|l|}{ Laterality } \\
\hline Left & $0.435(0.366-0.515)$ & 0.000 & $1.014(0.829-1.240)$ & 0.890 & $0.365(0.320-0.417)$ & 0.000 & $0.886(0.764-1.028)$ & 0.111 \\
\hline Right & $0.433(0.365-0.514)$ & 0.000 & $1.018(0.833-1.245)$ & 0.861 & $0.368(0.323-0.420)$ & 0.000 & $0.900(0.776-1.044)$ & 0.166 \\
\hline Other & 1 & & 1 & & 1 & & 1 & \\
\hline \multicolumn{9}{|l|}{ Histology } \\
\hline IDC & $0.832(0.789-0.876)$ & 0.000 & $0.941(0.889-0.995)$ & 0.033 & $0.958(0.932-0.984)$ & 0.002 & $0.986(0.959-1.014)$ & 0.330 \\
\hline ILC & $0.702(0.644-0.764)$ & 0.000 & $0.955(0.873-1.045)$ & 0.315 & $0.942(0.905-0.981)$ & 0.004 & $1.017(0.976-1.060)$ & 0.421 \\
\hline Mix/Other & 1 & & 1 & & 1 & & 1 & \\
\hline \multicolumn{9}{|l|}{ Grade } \\
\hline I & 1 & & 1 & & 1 & & 1 & \\
\hline II & $1.102(0.999-1.216)$ & 0.052 & $1.081(0.977-1.194)$ & 0.132 & $1.092(1.062-1.124)$ & 0.000 & $1.004(0.975-1.034)$ & 0.769 \\
\hline III & 1.448 (1.317-1.591) & 0.000 & $1.440(1.303-1.591)$ & 0.000 & 1.405 (1.364-1.447) & 0.000 & 1.158 (1.119-1.199) & 0.000 \\
\hline IV & $2.016(1.596-2.547)$ & 0.000 & 1.805 (1.424-2.288) & 0.000 & $1.464(1.245-1.722)$ & 0.000 & $1.138(0.966-1.340)$ & 0.121 \\
\hline Unknown & $2.086(1.871-2.325)$ & 0.000 & 1.328 (1.184-1.489) & 0.000 & 1.618 (1.544-1.695) & 0.000 & 1.095 (1.040-1.153) & 0.001 \\
\hline T stage & & & & & & & & \\
\hline T0 & 1 & & 1 & & 1 & & 1 & \\
\hline $\mathrm{T} 1$ & $0.394(0.313-0.495)$ & 0.000 & $0.751(0.579-0.974)$ & 0.031 & $0.574(0.502-0.655)$ & 0.000 & $1.191(1.028-1.380)$ & 0.020 \\
\hline $\mathrm{T} 2$ & $0.467(0.373-0.586)$ & 0.000 & $0.832(0.644-1.076)$ & 0.162 & $0.737(0.644-0.842)$ & 0.000 & $1.357(1.172-1.571)$ & 0.000 \\
\hline T3 & $0.519(0.413-0.652)$ & 0.000 & $0.922(0.712-1.194)$ & 0.539 & $0.859(0.749-0.985)$ & 0.029 & $1.494(1.287-1.734)$ & 0.000 \\
\hline $\mathrm{T} 4$ & $0.704(0.561-0.884)$ & 0.002 & $0.991(0.767-1.280)$ & 0.943 & $1.280(1.116-1.468)$ & 0.000 & $1.728(1.491-2.003)$ & 0.000 \\
\hline $\mathrm{TX}$ & $0.940(0.738-1.196)$ & 0.612 & $0.900(0.695-1.165)$ & 0.424 & 1.638 (1.408-1.907) & 0.000 & $1.382(1.181-1.617)$ & 0.000 \\
\hline N stage & & & & & & & & \\
\hline No & 1 & & 1 & & 1 & & 1 & \\
\hline N1 & $1.134(1.078-1.194)$ & 0.000 & $1.056(1.000-1.116)$ & 0.049 & $1.278(1.246-1.310)$ & 0.000 & 1.097 (1.066-1.128) & 0.000 \\
\hline N2 & $1.037(0.974-1.103)$ & 0.254 & $1.082(1.013-1.156)$ & 0.020 & $1.312(1.263-1.362)$ & 0.000 & $1.126(1.080-1.174)$ & 0.000 \\
\hline N3 & $1.164(1.094-1.240)$ & 0.000 & 1.133 (1.059-1.213) & 0.000 & $1.540(1.478-1.604)$ & 0.000 & 1.205 (1.151-1.261) & 0.000 \\
\hline NX & $2.416(2.151-2.713)$ & 0.000 & $1.356(1.190-1.545)$ & 0.000 & $3.227(2.941-3.540)$ & 0.000 & $1.322(1.191-1.467)$ & 0.000 \\
\hline Intrinsic type & & & & & & & & \\
\hline Luminal A & $0.632(0.584-0.684)$ & 0.000 & $0.808(0.745-0.877)$ & 0.000 & $0.902(0.863-0.943)$ & 0.000 & 1.035 (0.989-1.083) & 0.143 \\
\hline Luminal B & $0.693(0.629-0.765)$ & 0.000 & $0.769(0.695-0.851)$ & 0.000 & $1.012(0.957-1.070)$ & 0.667 & $1.032(0.974-1.092)$ & 0.285 \\
\hline HER2-enriched & $0.781(0.702-0.868)$ & 0.000 & $0.933(0.836-1.041)$ & 0.216 & $1.158(1.083-1.238)$ & 0.000 & $1.146(1.070-1.228)$ & 0.000 \\
\hline Triple-negative & $0.967(0.890-1.051)$ & 0.435 & $1.372(1.256-1.500)$ & 0.000 & $1.304(1.240-1.372)$ & 0.000 & 1.425 (1.351-1.503) & 0.000 \\
\hline Unknown & 1 & & 1 & & 1 & & 1 & \\
\hline Surgery & & & & & & & & \\
\hline Yes & $0.445(0.425-0.466)$ & 0.000 & $0.581(0.544-0.620)$ & 0.000 & $0.350(0.338-0.362)$ & 0.000 & $0.569(0.542-0.598)$ & 0.000 \\
\hline No/Unknown & 1 & & 1 & & 1 & & 1 & \\
\hline Radiotherapy & & & & & & & & \\
\hline Yes & $0.788(0.742-0.836)$ & 0.000 & $0.833(0.783-0.887)$ & 0.000 & $0.772(0.748-0.797)$ & 0.000 & $0.821(0.794-0.848)$ & 0.000 \\
\hline No/Unknown & 1 & & 1 & & 1 & & 1 & \\
\hline Chemotherapy & & & & & & & & \\
\hline Yes & $0.842(0.807-0.879)$ & 0.000 & $0.883(0.837-0.930)$ & 0.000 & $1.131(1.108-1.155)$ & 0.000 & $0.895(0.871-0.920)$ & 0.000 \\
\hline No/Unknown & 1 & & 1 & & 1 & & 1 & \\
\hline Sites of metasta & & & & & & & & \\
\hline No & 1 & & 1 & & 1 & & 1 & \\
\hline Bone only & $1.436(1.348-1.529)$ & 0.000 & 1.168 (1.084-1.259) & 0.000 & $2.057(1.956-2.163)$ & 0.000 & $1.333(1.257-1.414)$ & 0.000 \\
\hline Brain only & $3.285(2.711-3.982)$ & 0.000 & $2.200(1.799-2.688)$ & 0.000 & $4.314(3.652-5.097)$ & 0.000 & $2.531(2.130-3.007)$ & 0.000 \\
\hline Liver only & 1.441 (1.162-1.787) & 0.001 & 1.337 (1.076-1.662) & 0.009 & $2.123(1.763-2.555)$ & 0.000 & $1.500(1.245-1.809)$ & 0.000 \\
\hline Lung only & $2.053(1.775-2.375)$ & 0.000 & $1.352(1.163-1.572)$ & 0.000 & $2.775(2.451-3.142)$ & 0.000 & 1.573 (1.384-1.787) & 0.000 \\
\hline Multiple & $2.443(2.302-2.593)$ & 0.000 & $1.816(1.686-1.957)$ & 0.000 & $3.651(3.473-3.839)$ & 0.000 & $2.072(1.946-2.206)$ & 0.000 \\
\hline
\end{tabular}

differentiated; Grade III, poorly differentiated; Grade IV, undifferentiated anaplastic; OR, odds ratio; CI, confidence interval. 

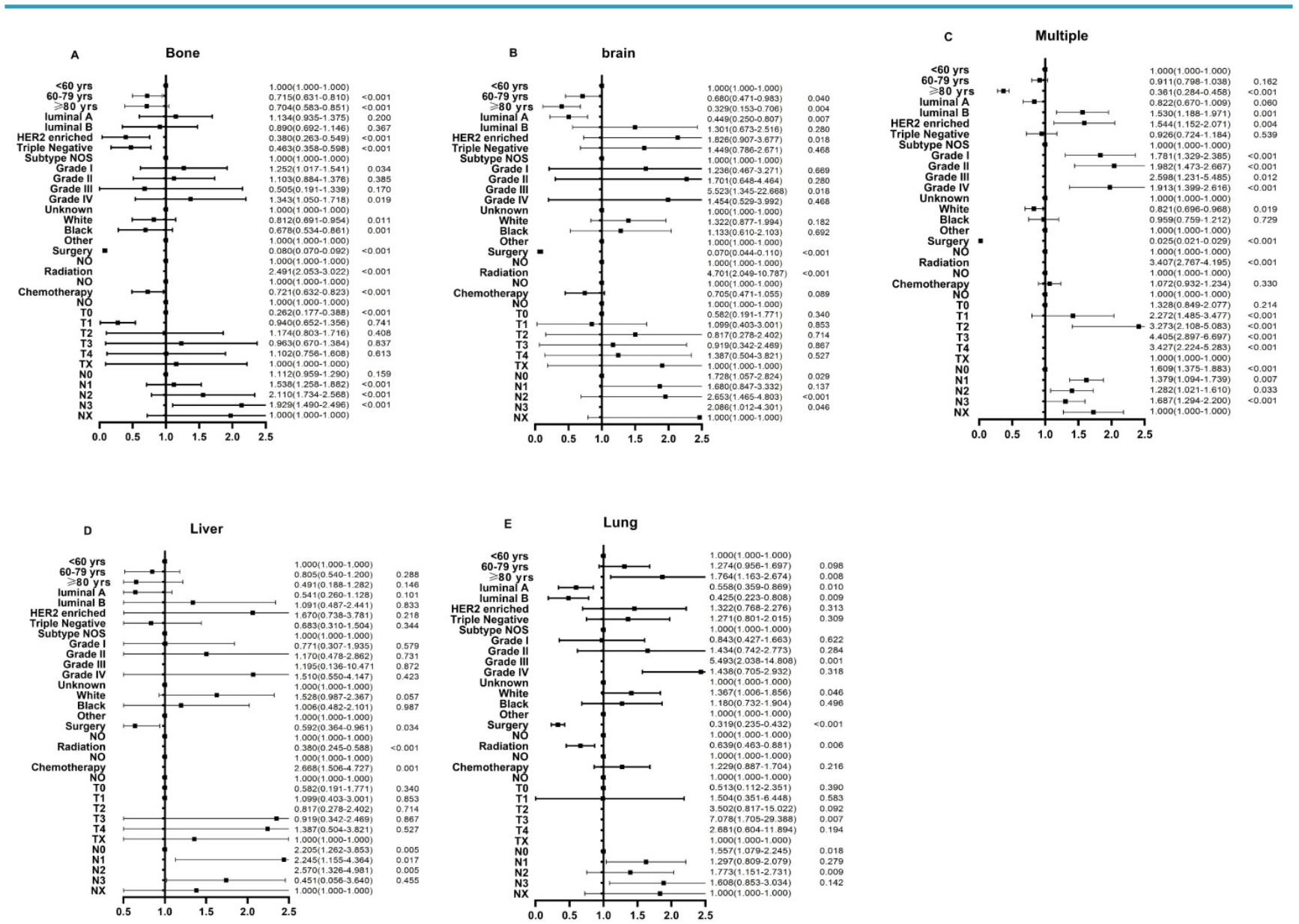

Figure 3. Multivariable logistic regression analyses predicting different sites of metastasis in breast cancer patients. (A) bone only metastasis; (B) brain only metastasis; (C) multiple metastatic sites; (D) liver only metastasis; and (E) lung only metastasis.

\section{Discussion}

As the US population ages, the number of older adults with BC is also rising. Nevertheless, only a few studies have focused on older patients, especially those aged $\geq 80$ years. Lewis et al. found that only $3 \%$ of patients participating in BC clinical trials were aged $>70$ years, and the possible reasons for this were low compliance to treatment and a high rate of comorbidities influencing mortality, treatment costs, and expected benefits [11]. In the present study, older patients with BC had more distinct clinical presentation and prognosis than younger individuals, which is consistent with previous findings $[12,13]$. In our cohort, we found that several clinicopathological parameters varied significantly among different age groups. Moreover, we observed distinct metastasis patterns in patients aged $\geq 80$ years. Our results also show that after adjusting for related parameters, age at diagnosis had a worse independent effect and was a prognostic factor with respect to $B C$ with distant metastases.

There seems to be a debate on distant metastases of $B C$ in different age groups. Yancik et al. showed that older women were more likely to have distal metastases than younger women in a study of 118,000 women with BC [14]. However, other investigators have demonstrated that compared to women aged $<$ 65 years, those aged $\geq 65$ years were more likely to have early-stage cancers [15]. Another study that recruited 243,896 patients showed that in patients with brain or liver metastasis, $64.4 \%$ were aged $<65$ years. Those with three and four metastasis sites accounted for $65.6 \%$ and $73.3 \%$, respectively, of those aged $<65$ years, suggesting that they were more likely to have metastasis [16]. Regarding the impact of age in this study, we found that older ( $\geq 80$ years) patients had a lower risk of bone, brain, liver, and multiple metastases but a higher risk of lung metastasis, which is consistent with previous findings $[17,18]$. Indeed, the different patterns of distant metastasis in older patients might be due to many factors. One important factor is the time of diagnosis of BC in patients aged $\geq$ 80 years and the time at which they underwent mammography screening prior to the diagnosis [19]. Another factor is the different subtypes of breast carcinoma $[20,21]$. Several previous reports showed that both the HER2 and triple-negative subtypes were 
significantly associated with brain metastasis, while the HER2 subtype showed a similar incidence of liver metastasis to the luminal B subtype [21,22]. Furthermore, Soni et al. found that liver metastases were more frequent in patients with the HER2+ subtype than in those with the luminal B, luminal A, and triple-negative subtypes [23]. Comparatively, our results indicate that patients with HER2-enriched BC aged $\geq 80$ years had fewer occurrences of brain-only or liver-only metastatic disease [24]. The possible reasons for these disparities may be as follows: first,
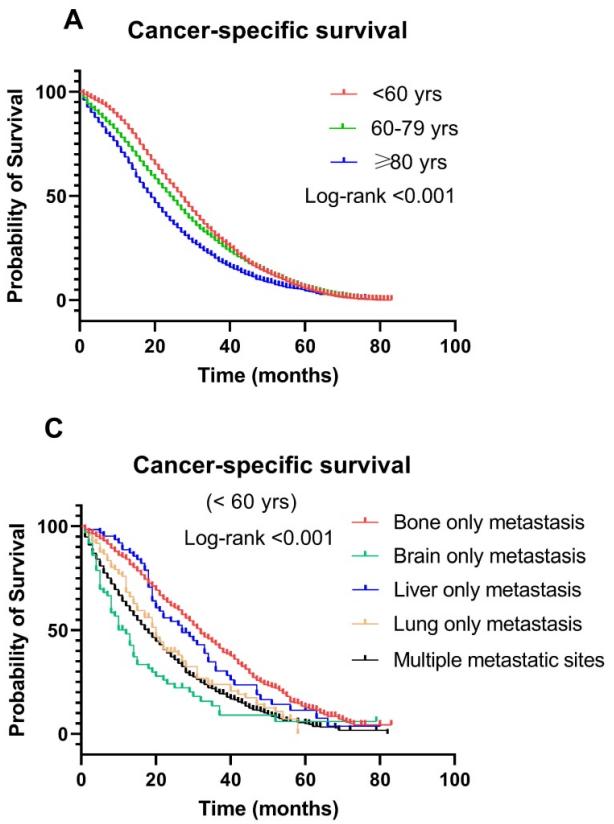

E

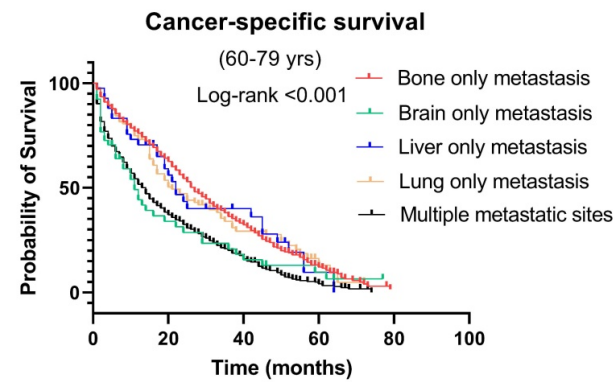

G

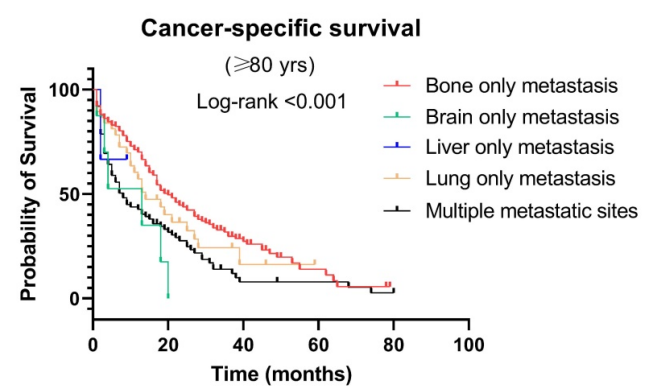

our results should be interpreted cautiously since there were relatively few patients with triple-negative and HER2+ BC in our patient cohort, and second, there were more patients with luminal A subtype of $\mathrm{BC}$ in those aged 80 years and older, which is in line with a previous study showing that the group diagnosed at an age above 60 years had a higher percentage of ER/PR-positive BC than patients aged $\leq$ 60 years [25]. Thus, the mechanism explaining the risk of distant metastases in $\mathrm{BC}$ patients aged $\geq 80$ years remains to be elucidated.
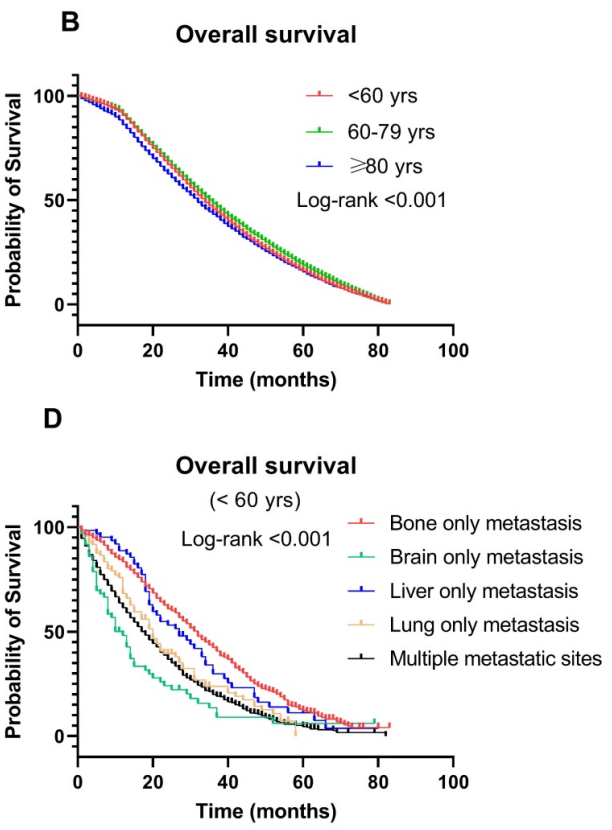

$\mathbf{F}$

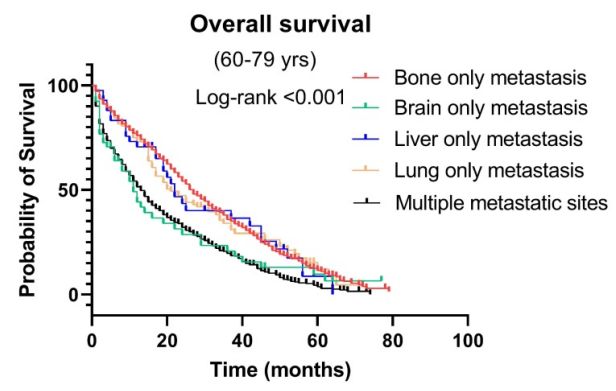

H

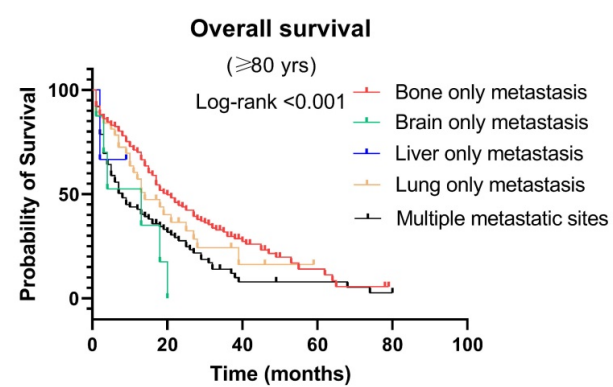

Figure 4. Kaplan-Meier curve of (A) cancer-specific survival and (B) overall survival by age groups among breast cancer patients with metastases; Kaplan-Meier curve of cancer-specific survival and overall survival according to metastasis sites in (C-D) younger ( $<60$ years); (E-F) middle-aged (60-79 years); and (G-H) older ( $\geq 80$ years) patients with breast cancer. 
In our analysis, Cox multivariate analyses showed that patients with older age had worse CSS and OS than younger individuals. Indeed, the worst prognosis in the older group ( $\geq 80$ years) was related to poorer physical health and receipt of less aggressive treatment because of age-related deterioration of organ function or comorbidities. A previous study revealed that $\mathrm{BC}$ patients aged over 80 years were less likely to receive optimal chemotherapy as their initial treatment than those aged 65 to 75 (11.3\% vs. $35.4 \%)$ [26]. Furthermore, in our population, we found that older patients also had a lower rate of locoregional therapy, such as radiation therapy or surgery, over the entire study period, which is in accordance with previous studies $[19,27]$. Recently, there exists a controversy regarding whether women aged $\geq 80$ years benefit from locoregional control as much as younger women, especially in patients that present with distant metastases. Additionally, another explanation might be that potential targeted therapy was associated with improved survival among patients aged $<65$ years [28]. In fact, several retrospective studies have shown that the benefits and safety of optimal treatment were maintained in patients aged $>75$ years [8]. Thus, elderly patients still require optimizated care with a view to curative treatment.

Another interesting finding of our study is the different survival outcomes following different patterns of metastasis. To be specific, patients with only bone metastasis had the best CSS and OS in all metastatic patterns among all age groups. The brain-only metastasis group had the poorest outcomes in the middle-aged and younger groups. This might be explained by a low proportion of effective therapy given to patients with brain-only metastasis. Interestingly, for the older group, liver-only metastasis showed significantly worse CSS and OS than the other metastatic patterns. In other words, viable therapeutic alternatives are required for women aged $<60$ years with only brain metastases and women aged $\geq 80$ years with only liver metastases.

There are some limitations to our study. This was a retrospective study with limited data, and the SEER database provides limited information on systemic treatments, such as endocrine therapy and targeted therapy, which might have influenced survival outcomes. In addition, we were not able to incorporate clinical parameters of patients, such as performance status, details on comorbidities, and the sample size of older women, in our analyses as these data were limited in the SEER database. Despite these limitations, valuable data were provided in this database for analyzing patterns in BC cases with distant metastases across the United States.

\section{Conclusion}

In conclusion, our investigation evidenced novel findings regarding the outcomes of older patients with metastatic BC that women aged $\geq 80$ years had a distinctive metastasis pattern, received the least amount of anti-cancer therapy, and had the worst survival outcomes.

Thus, using population-based data from the SEER, our findings summarize the metastasis patterns and survival outcomes of BC patients in three different age groups. The patients aged $\geq 80$ years were less likely to be receptive to cancer-related therapy and had the highest rate of cancer mortality among all patients. Therefore, our findings will hopefully help clinicians offer more reasonable modalities of cancer treatment to elderly patients with BC.

\section{Abbreviations}

BC: breast cancer; OS: overall survival; CSS: cancer-specific survival; SEER: Surveillance, Epidemiology, and End Results.

\section{Acknowledgements}

We would like to thank all the staff of the National Cancer Institute for their efforts in the SEER program.

\section{Funding Statement}

This work was supported by the National Natural Science Foundation of China (82002551, 81772619), Science and Technology Project of Tianjin Municipal Health Commission (KJ20119), National Key Research and Development Program of China (2016YFC0901401), Bethune Charitable FoundationExcelsior Surgical Fund (HZB-20190528-18), and Clinical Trial Project of Tianjin Medical University (2017kylc006).

\section{Competing Interests}

The authors have declared that no competing interest exists.

\section{References}

1. Siegel RL, Miller RD, Jemal A. Cancer statistics, 2019. CA: A Cancer Journal for Clinicians. 2019; 69: 7-34.

2. Ortman JM, Velkoff VA, Howard H. An aging nation: the older population in the United States, Current Population Reports. U.S. Census Bureau. 2014; 25-1140.

3. Manders K, van de Poll-Franse LV, Creemers GJ. Clinical management of women with metastatic breast cancer: A descriptive study according to age group. BMC Cancer. 2006; 6: 179.

4. Dunn C, Wilson A, Sitas F. Older cancer patients in cancer clinical trials are underrepresented. Systematic literature review of almost 5000 meta- and pooled analyses of phase III randomized trials of survival from breast, prostate and lung cancer. Cancer Epidemiology. 2017; 51: 113-117. 
5. Enger SM, Thwin SS, Buist DS, Field T, Frost F, Geiger AM, et al. Breast cancer treatment of older women in integrated health care settings. Journal of Clinical Oncology. 2006; 24: 4377-4383.

6. Kaplan HG, Malmgren JA, Atwood MK. Triple-negative breast cancer in the elderly: prognosis and treatment. Breast Journal. 2017; 23: 630-637.

7. Smith BD, Jiang J, McLaughlin SS, Hurria A, Smith GL, Giordano SH, et al. Improvement in breast cancer outcomes over time: are older women missing out. Journal of Clinical Oncology. 2011; 29: 4647-4653.

8. Jeon YW, You SH, Lee JE, Youn HJ, Lim W, Han JH, et al. Optimal treatment of breast cancer in women older than 75 years: a Korea Breast Cancer Registry analysis. Breast Cancer Research and Treatment. 2019; 178: 693-701.

9. Kalinowski L, Saunus LM, McCart Reed AE, Lakhani S. Breast cancer heterogeneity in primary and metastatic disease. Advances in Experimental Medicine and Biology. 2019; 1152: 75-104.

10. Park HS, Lloyd S, Decker RH, Wilson LD, Yu JB. Overview of the surveillance, epidemiology, and end results database: evolution, data variables, and quality assurance. Current Problems in Cancer. 2012; 36: 183-190.

11. Lewis JH, Kilgore ML, Goldman DP, Trimble EL, Kaplan R, Montello MJ, et al. Participation of patients 65 years of age or older in cancer clinical trials. J. Clin.Oncol, 2003; 21: 1383-1389.

12. Wildiers H, Kunkler I, Biganzoli L, Fracheboud J, Vlastos G, Bernard-Marty C, et al. Management of breast cancer in elderly individuals: recommendations of the International Society of Geriatric Oncology. The Lancet Oncology. 2007; 8: $1101-1115$

13. Cheung KL, Wong AW, Parker H, Li VWY, Winterbottom L, Morgan DAL, et al. Pathological features of primary breast cancer in the elderly based on needle core biopsies-a large series from a single centre. Critical Reviews in Oncology and Hematology. 2008; 67: 263-267.

14. Yancik R, Ries LG, Yates JW. Breast cancer in aging women. A population-based study of contrasts in stage, surgery, and survival. Cancer. 1989; 63: 976-981.

15. Lyman GH, Lyman S, Balducci L, Kuderer N, Reintgen D, Cox C, et al.Age and the risk of breast cancer recurrence. Cancer Control. 1996; 3: 421-427

16. Wu Q, Li J, Zhu S, Wu J, Chen C, Liu Q, et al. Breast cancer subtypes predict the preferential site of distant metastases: a SEER based study. Oncotarget. 2017; 8: 27990-27996

17. Schouten LJ, Rutten J, Huveneers HA, Twijnstra A. Incidence of brain metastases in a cohort of patients with carcinoma of the breast, colon, kidney, and lung and melanoma. Cancer. 2002; 94: 2698-2705.

18. Evans AJ, James JJ, Cornford EJ, Chan SY, Burrell HC, Pinder SE, et al. Brain metastases from breast cancer: identification of a high-risk group. Clinical Oncology (Royal College of Radiologists (Great Britain)). 2004; 16: 345-349.

19. Badgwell BD, Giordano SH, Duan ZZ, Fang S, Bedrosian I, Kuerer HM, et al. Mammography before diagnosis among women age 80 years and older with breast cancer. Journal of Clinical Oncology. 2008; 26: 2482-2488.

20. Kast K, Link T, Friedrich K, Petzold A, Niedostatek A, Schoffer O, et al. Impact of breast cancer subtypes and patterns of metastasis on outcome. Breast Cancer Research and Treatment. 2015; 150: 621-629.

21. Kennecke H, Yerushalmi R, Woods R, Cheang MCU, Voduc D, Speers CH, et al. Metastatic behavior of breast cancer subtypes. Journal of Clinical Oncology. 2010; 28: 3271-3277.

22. Smid M, Wang Y, Zhang Y, Sieuwerts AM, Yu J, Klijn JGM, et al. Subtypes of breast cancer show preferential site of relapse. Cancer Research. 2008; 68: 3108-3114.

23. Soni A, Ren Z, Hameed O, Chanda D, Morgan CJ, Siegal GP, et al. Breast cancer subtypes predispose the site of distant metastases. American Journal of Clinical Pathology. 2015; 143: 471-478

24. Colzani E, Johansson ALV, Liljegren A, Foukakis T, Clements M, Adolfsson J, et al. Time-dependent risk of developing distant metastasis in breast cancer patients according to treatment, age and tumour characteristics. British Journal of Cancer. 2014; 110: 1378-1384.

25. Ferrigni E, Bergom C, Yin Z, Szabo A, Kong AL. Breast cancer in women aged 80 years or older: An analysis of treatment patterns and disease outcomes. Clinical Breast Cancer. 2019; 19: 157-164.

26. Bertolo A, Rosso C, Voutsadakis IA. Breast cancer in patients 80 years-old and older. European Journal of Breast Health. 2020; 16: 208-212.

27. Vetter M, Huang DJ, Bosshard G, Guth U. Breast cancer in women 80 years of age and older: A comprehensive analysis of an underreported entity. Acta Oncologica. 2013; 52: 57-65

28. Daniels B, Kiely BE, Tang M, Tervonen H, Pearson SA. Trastuzumab use in older patients with HER2-positive metastatic breast cancer: outcomes and treatment patterns in a whole-of-population Australian cohort (2003-2015). BMC Cancer. 2019: 19: 909. 